\title{
Digital Control of High DC Voltage Converter Based on Cockcroft Walton Voltage Multiplier Circuit
}

\author{
K. S. Muhammad, A. M. Omar and S. Mekhilef
}

\begin{abstract}
A new method of controlling high DC voltage based on Cockcroft Walton Voltage Multiplier circuit by using digital controller is presented. The digital controller is developed using Complex Programmable Logic Devices (CPLD). The proposed system utilizes a single-phase $\mathrm{AC}$ as an input supply. The power switching devices in the controlled bridge are controlled by the multiple-pulse Pulse Width Modulation (PWM) switching technique so as to minimize the low order harmonic present on the AC side of the converter system. A low pass filter is incorporated in the circuit to filter out unwanted harmonics and to give a sinusoidal AC current. A high frequency transformer with 1:1 ratio is incorporated in the design to provide galvanic isolation for better circuit performance and protection. The optimum operation of transformer core in four quadrant of B-H curve is also considered in the proposed converter topology. The laboratory model of the converter is developed and tested. The experimental result is compared with the simulation result.
\end{abstract}

Index Terms - Cockcroft Walton, Complex Programmable Logic Devices (CPLD), and Pulse Width Modulation (PWM)

\section{INTRODUCTION}

$\mathrm{T}$ HE demand from physicists for very high DC voltage forced the improvement of rectifying circuit quite early. It is obvious that every multiplier circuit in which transformer, rectifiers and capacitor unit have only to withstand a fraction of the total output voltage will have great advantages. Today they are many standard cascade circuits available for the conversion of modest AC to high DC voltage. However this project only treated on Cockcroft-Walton type.

Conventionally, multi-stage power conversion with AC$\mathrm{DC}-\mathrm{AC}-\mathrm{DC}$ is used to generate a high DC voltage. This technique does not require a sophisticated controller to control the operation. However, due to the inherent characteristics of a multi-stage system, it requires more components. The lower orders of harmonics are dominant in the uncontrolled bridge topology and require a large LC filter size to minimize these

Manuscript received April 30, 2005. This work was supported in part by the Faculty of Electrical Engineering, Universiti Teknologi MARA, Malaysia. K. S. Muhammad is with the Faculty of Electrical Engineering, Universiti Teknologi MARA, 40450 Shah Alam, Selangor, Malaysia

A. M. Omar is with the Faculty of Electrical Engineering, Universiti Teknologi MARA, 40450 Shah Alam, Selangor, Malaysia

S. Mekhilef (corresponding author) is with the Department of Electrical Engineering, University of Malaya, 50603, Kuala Lumpur, Malaysia (e-mail: saad@um.edu.my, Tel: 00-603-79676851, Fax: 00-603-79675316) effects. A low-power active filter can also be used to control the harmonic current, but at some additional cost. The high DC voltage can also be generated using a simple AC-DC topology, which consists of a high ratio of a step-up transformer but requires a large size of transformer. Although the topology is simple, the harmonic current generated is uncontrollable [1]

High direct voltages are required for several type of dielectric diagnosis test, usually formed on non-destructive tests, on insulation structure, as well as for research and high voltage effects under DC [2].

There is a few methods to control the output of the Cockcroft Walton circuit such as varying the modulation index of the switching pulses, frequency of the input voltage, varying the duty cycle of the switching pulses and etc. These control technique can be done by using analog and digital method. This paper concentrates only in varying the modulation index (varying the width of switching pulses either wide or narrow) by using digital control method. The switching method is by using PWM switching technique. This is done by using Xilinx Foundation Series software and then downloads it into XC95108 chip.

\section{SYSTEM CONFIGURATION}

The principle of operation of the Cockcroft Walton is based on built-up energy in the inductor winding during switch-on. During the positive cycle, M1 and M2 are switched on.

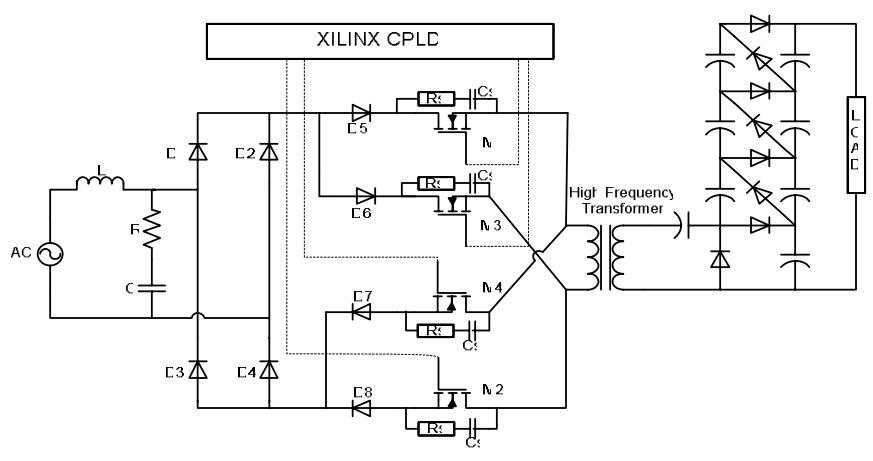

Fig.1. The proposed converter circuit

This will charge the coupling transformer and operate the transformer core in the first quadrant of B-H curve. While during the negative cycle $\mathrm{M} 3$ and $\mathrm{M} 4$ need to turn on and this will operates the transformer in the third quadrant of $\mathrm{B}-\mathrm{H}$ 
curve. Hence, this will fully utilized the transformer B-H curve. Consequently, more power can be delivered to the secondary circuit. The energy from the transformer is transferred into the capacitor and load during both switching cycle. The rate of energy transferred is determined from the percentage of duty cycle which controlled by the modulation index. More energy will be transferred to the capacitor at higher modulation index and thus a higher DC voltage will be produce [3]. The proposed converter circuit is shown in Figure 1 which consists of a low pass LC filter with resistor damper R, four IGBTs (M1, M2, M3 and M4) of type BUP314, snubber circuit Cs and Rs, eight fast switching diodes (D1 until D8) of type RHRP30120 and a high-frequency transformer with 20 turns on both sides.

During the positive cycle, the current flows from $\mathrm{AC}$ source-filter-D2-MA-D3-M1-transformer-M2-D8-MB-D5 and back to supply. During this time, the coupling transformer charging up and operate the transformer core in the first quadrant of B-H curve as shown in Fig. 2.

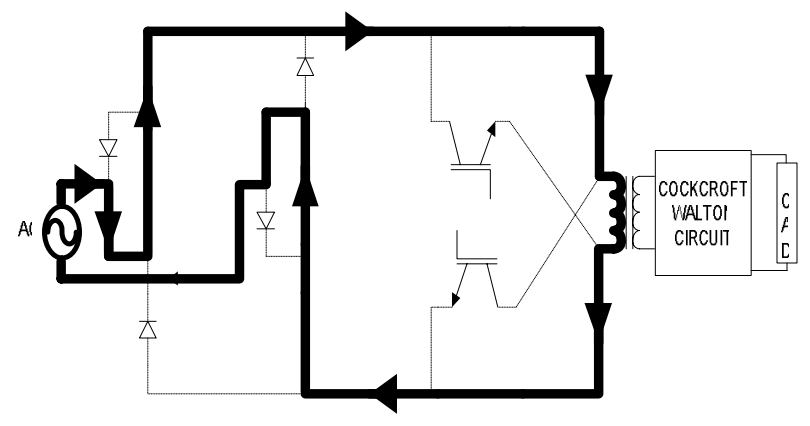

Fig. 1: Positive flow

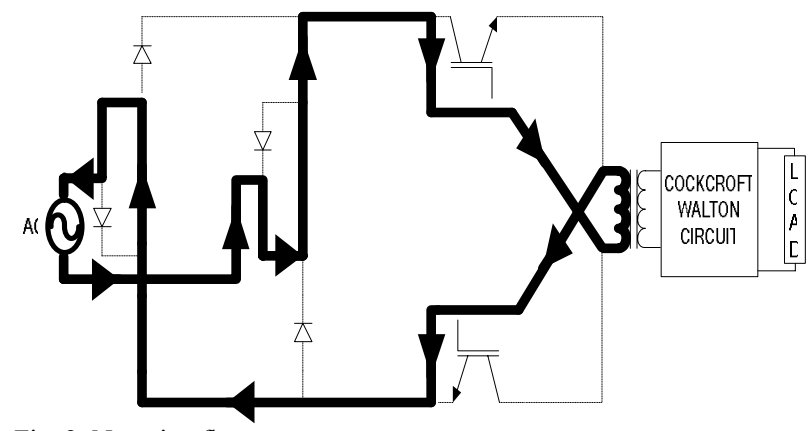

Fig. 2: Negative flow

During negative cycle the current flows from $\mathrm{AC}$ source through D6-MB-D7-M3-transformer-M4-D4-MA-D1 and back to AC supply. This operates the transformer in the third quadrant of B-H curve, thus fully utilizing the transformer magnetizing cycle. Consequently, more power can be delivered to the secondary circuit. The energy from the transformer is transferred into the capacitor and load during both switching cycles. The rate of energy transfer is determined from the percentage duty cycle of the pulses. More energy will be transferred to the capacitor at higher modulation index and thus a higher DC voltage will be produce [3-4].

\section{SWITCHIN STRATEGIES}

SPWM is a well known as wave shaping technique in power electronics converter system. For realizing SPWM, a high frequency triangular carrier signal, $V_{C}$, is compared with a sinusoidal reference signal, $V_{R}$, of the desired frequency, and the crossover points are used to determine the switching instants. When sinusoidal signal has magnitude higher than or equal to the triangular signal the comparator output is high, otherwise it is low as shown in Figure 4.

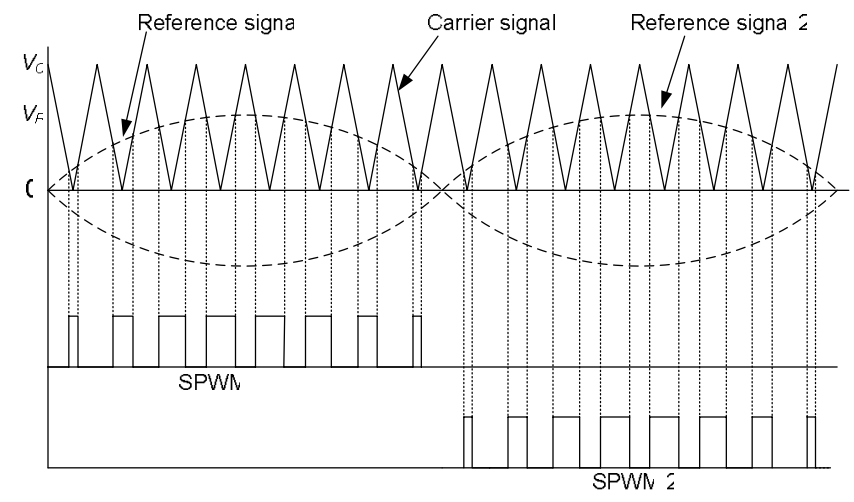

Fig. 4. SPWM Generation

The counter output (carrier signal) is compared with the set external data and a PWM signal for triggering M1 and M2 is generated. To generate triggering pulses for $\mathrm{MA}$ and $\mathrm{MB}$, the output from comparator $\mathrm{B}$ and $\mathrm{A}$ is combined using $\mathrm{OR}$ gate and the result is shown in Figure5.

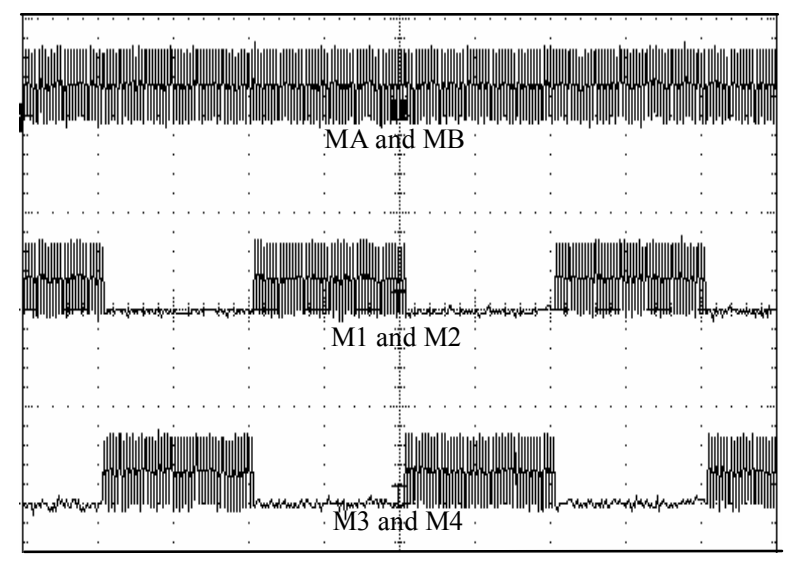

Fig.5. Experimental result of IGBT triggering pulse of $20 \mathrm{kHz}$ carrier frequency at modulation index 0.5

(scale Y: $2.5 \mathrm{~V} / \mathrm{div}$, scale $\mathrm{X}: 5 \mathrm{~ms} / \mathrm{div}$ )

\section{COCKCROFT-WALton}

The Cockcroft-Walton circuit is a voltage booster circuit with an array of series-connected diodes and capacitors as shown in Figure 6. When a reference voltage is applied to this circuit, voltage potentials are boosted depend on the number of stages used (multiplied by integer). This circuit delivers good linearity in both DC and pulsed currents while maintaining low power consumption and allow compact circuit design. [5]. 


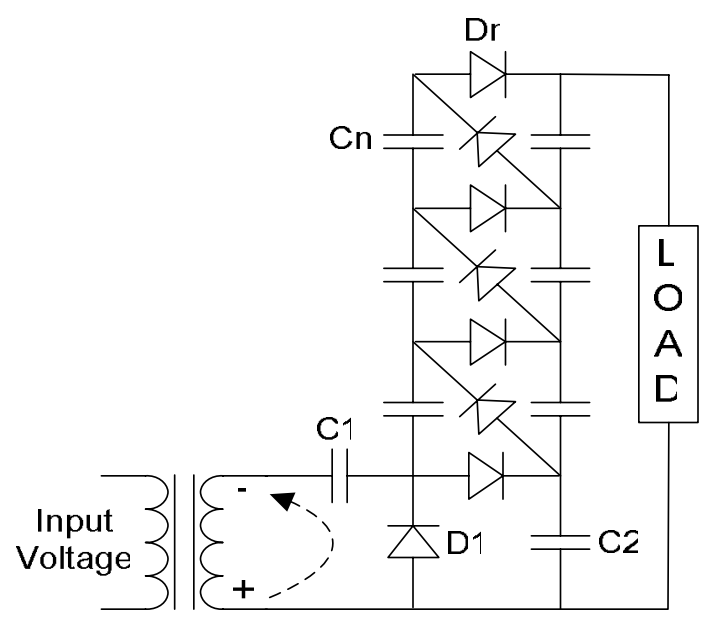

Fig.6. Cockcroft Walton circuit

The principle operation of the converter is as follows. Referring to Figure 6, capacitor $\mathrm{C} 1$ charged in the direction shown in the negative half cycle to the maximum value of the AC supply via diode D1. During the positive half cycle, the charge on capacitor $\mathrm{Cl}$ aids the $\mathrm{AC}$ supply, so that the capacitor $\mathrm{C} 2$ is charged twice the maximum supply voltage. The same is repeated at the next stage of the cascaded capacitors and diodes. In practice, with load and volt-drops, the value will be reduced [6-8].

Due to the configuration of the converter (refer Figure 1) and the switching technique (refer Figure 4), the current will charge and discharge the transformer such that the output increases rapidly producing a high DC voltage.

\section{Simulation And EXPERIMENTAl Results}

PSpice simulation software was used to simulate the circuit prior to implementation, while the laboratory model of the proposed converter is developed using components below. The carrier frequency was set to $20 \mathrm{kHz}$. The display measurement was obtained by means of TDS-210 oscilloscope from Textronix. The converter has been tested with following parameters:

Input voltage $\mathrm{V}_{\mathrm{L}}=15 \mathrm{~V}$

Modulation index $=0.1$ to 0.9

Load $=2 \mathrm{M} \Omega$

Input filter parameter, $\mathrm{L}=2 \mathrm{mH}, \mathrm{C}=2 \mathrm{uF}(\mathrm{AC})$

The voltage gain ratio obtained linearly increases as the modulation index increases as shown in Figure 7. Voltage gain can reach up to 100 . The voltage gain ratio is defined as the ratio of DC output voltage to the phase rms input voltage.

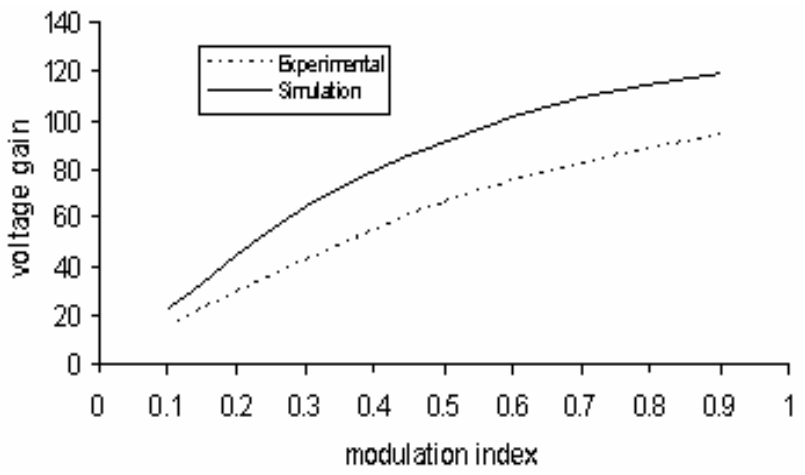

Fig.7.Effect of modulation index on the voltage gain ratio

\section{V.HARMONIC REDUCTION}

The switching action of the rectifying device inevitably results in non-sinusoidal current being drawn from the $\mathrm{AC}$ supply system. In essence, the AC supply delivers a sinusoidal voltage with power flow relating only to the fundamental (mains) frequency. The load then converts some of this power to higher frequencies, and transmits harmonic power back into the supply system. Hence a rectifying load acts in part as a harmonic generator. Figure 9 shows the experimental and simulation results of input supply current before filtering, while Figure 10 is input current waveform after filtering where the unwanted harmonic is eliminated.
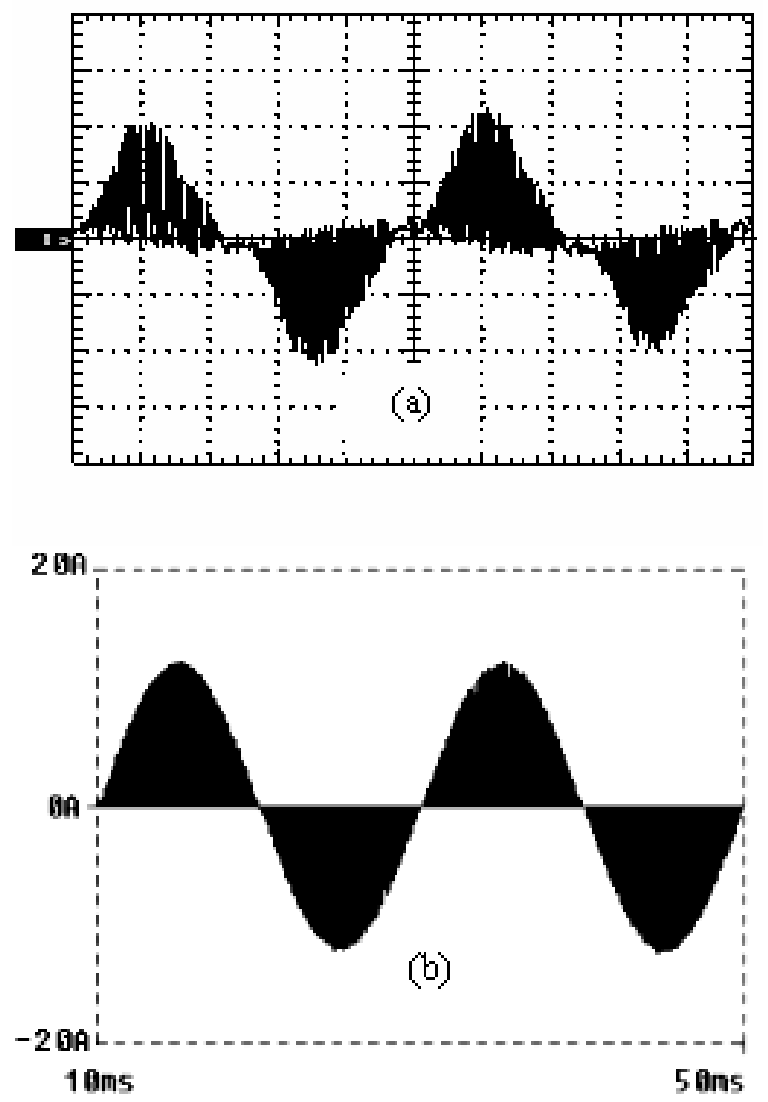

Fig. 9. Input current waveform before filtering. a) Experimental result (b) Simulation result (scale Y: $5 \mathrm{~A} / \mathrm{div}$, scale $\mathrm{X}: 4 \mathrm{~ms} / \mathrm{div}$ ) 

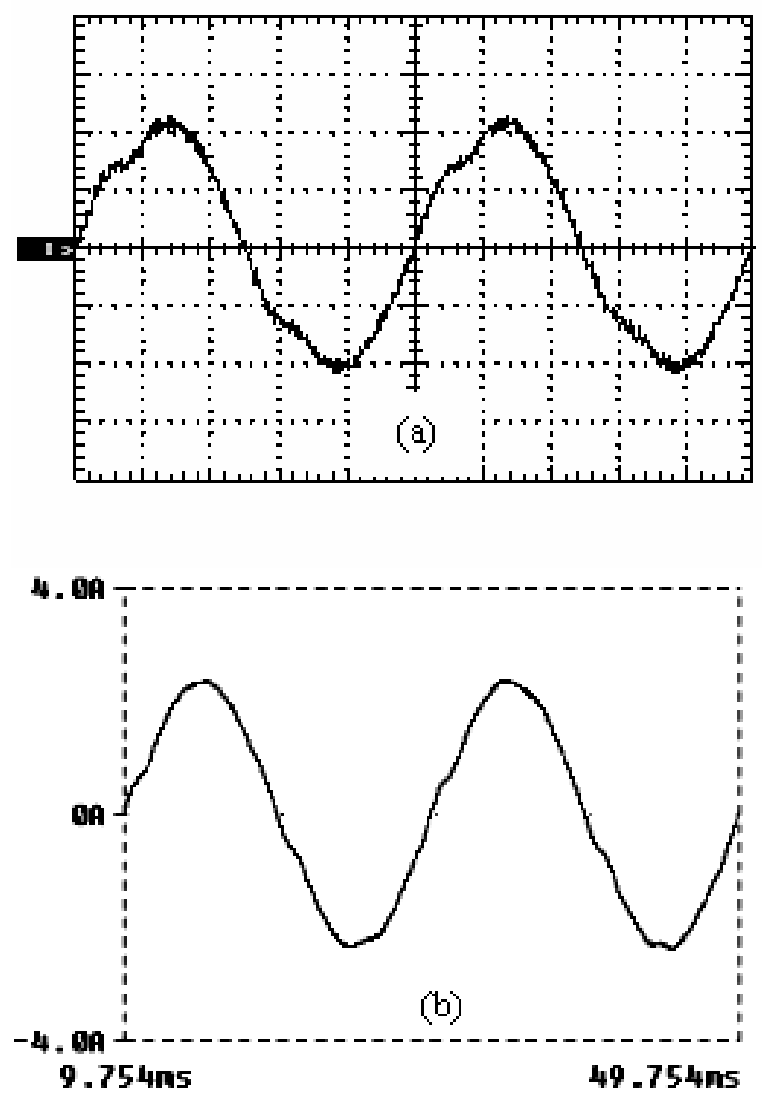

Fig.10. Input current waveform after filtering. a) Experimental result (b) Simulation result (scale Y: 1A/div, scale X: 4ms/div)

\section{CONCLUSION}

The performance of single-phase single-stage high DC voltage multiplier circuit has been demonstrated. The pulse width modulation technique used for switching the IGBTs shows that it can improve the quality of $\mathrm{AC}$ current injected back to the utility supply with less low order harmonics. The results also demonstrate that with a 1:1 transformer ratio, the voltage gain of Cockcroft Walton with four stages can be boost up to 100 . The DC output voltage is regulated externally using a modulation index. By using Xilinx CPLD to produce PWM signal it provides a convenient way to vary the width of PWM and regulate the output of high DC voltage.

\section{ACKNOWLEDGMENT}

This project is supported by IRPA, Malaysia. Project no. 0902-01-0029-EA0029

\section{REFERENCES}

[1] Yan Liu; Moschopoulos, G.; "A single-stage AC-DC Forward Converter with Input Power Factor Correction and Reduced DC Bus Voltage", The 25th International Telecommunications Energy Conference, 19-23 Oct. 2003 pp. $132-139$.

[2] Chun-Feng Jin; Ninomiya, T.; "Novel Soft-switched Single-stage ACDC Converter with Sow Line-current Harmonics and Low Outputvoltage Ripple", Power Electronics Specialists Conference 2001, vol. 2, 17-21 June 2001, pp. $660-665$.

[3] Moschopoulos, G.; Jain, P.; "Single-phase Single-stage Power-factorcorrected Converter Topologies", IEEE Transactions on Industrial Electronics vol. 52, Issue 1, Feb. 2005 pp. 23 - 35
[4] Garcia, O.; Cobos, J.A.; Prieto, R.; Alou, P.; Uceda, J.; "Simple AC/DC converters to meet IEC 1000-3-2", Applied Power Electronics Conference and Exposition 2000, vol. 1, 6-10 Feb. 2000, pp. 487 - 493.

[5] Rossetto, L.; Buso, S.; "Digitally-controlled single-phase single-stage AC/DC PWM converter", IEEE Transactions on Power Electronics, vol. 18, Issue 1, Jan. 2003, pp. $326-333$.

[6] Rahim N.A And Omar A.M; "Three-phase Single-Stage High-Voltage DC Converter", IEE Proceedings Generation, Transmission and Distribution, vol. 149, Issue: 5, Sept. 2002, pp. $505-509$

[7] Wang, J., Dunford, W., and Mauch, K., "A Comparison Between Some Proposed Boost Topologies and Conventional Topologies In Discontinuous Inductor Current Mode", Proceeding of $22^{\text {nd }}$ annual IEEE international Conference on Industrial Electronic, control and instrumentation (IECON) 1996, Vol. 3, pp. $1524-1529$.

[8] Lopez, O., Garcia De Vicuna, L., Matas, J., Castilla, M., and Lopez, M.: "A New Family of Single-Stage High Power-Factor AC/DC Converters", Proceeding of $31^{\text {st }}$ annual IEEE Power Electronic Specialist Conference. (PESC) 2000, Vol. 3, pp. 1445 - 1450. 